\title{
LA AFINIDAD POETICA DE LUGONES Y TABLADA
}

\author{
POR \\ IIUGO MENDEZ-RAMIREZ \\ University of Virginia
}

En una nota a un poema de José Juan Tablada, José Emilio Pacheco scñala la influencia de Leopoldo Lugones en la pocsía mexicana de principios de siglo, y especialmente en Tabladi.

No se ha estudiado el infujo de Leopoldo Lugones (1874-1938) en el modernismo mexicano. Su lectura fue decisiva para González de Lcón, Rebolledo Y López Velarde. Colaboró desde el primer número en la Revista Moderna y allí mismo Las montañas del oro recibieron el elogio entusiasta de Tablada. Seguranente ambos poetas entablaron correspondencia desde entonces, aunque no se conocieron hasta 1911 en Paris. (63, nota 5)

Castro Lcal, por su parte, en su introducción a las obras completas de González Marlíncz, afirma que José Juan Tablada (1871-1945) cn su libro Al sol y bajo la luna, "repclía sin novedad notas ya muy oídas c imitaba tardíamente Los crepúsculos del jardín de Lugones" (x). El mismo año (1971), Héctor Valdés hace mención de la serie de sonctos "Los doce goces" de Los crepúsculos del jardín dedicada a Tablada y publicada en el segundo número de la Revista Moderna (1898). "E1 tono de cstos sonctos - dice Valdés-denota claramente cl influjo que Lugones ejerció sobre el poeta mexicano .... El florilegio tiene composiciones de innegable ascendencia lugoniana" (624, nota 22$)$.

A pesar de que las observaciones anteriores no carecen de fundamento, distan mucho de ser un juicio objetivo que contribuya a aclarar dicha afinidad: cspecialmente cuando se trata de establecer fuentes litcrarias entre los modernistas. De hecho, en El florilegio (1898-1904)' de Tablada, la influencia es a la inversa como

${ }^{1}$ La primera edición de El Florilegio (1818) pertenece a la juventud de Tablada; y la segunda (1904) contiene sobre todo el carácter modernista de la época. Ver la introducción de Héctor Valdés a las obras completas de Tablada, pp. 12-13. 
vercmos más adclante. Un cstudio detallado de la obra poćtica de ambos autores revcla que cxistió una influencia mutua. Con esto, mi intención no es desmerecer la gran influencia de Lugones en Tablada, sino establecer de manera objetiva tal reciprocidad, dejando al lector sacar sus propias conclusiones. Tablada fue, como Lugones, un poeta sícmpre abicrto a las innovaciones del día; la trayectoria del mexicano coincide en muchos aspectos con la de Lugones, aunque su visión filosófica de la pocsía como clemento expresivo lleva diferentes necesidades cspirituales.

La larga traycctoria de Lugones (1897-1938) abarca 41 años. Su primer libro, Las montañas de oro (1897), "se inició con una poesía que se creía profética, visionaria, a ratos blasfema c incluso con algunas notas del repertorio decadentista ... donde resuenan la clocuencia sonora de Víctor Hugo y el ímpetu de Walt Whitman" (Olivio Jiméncz, 332). Despućs vinieron Los crepúsculos del jardín (1905), donde Lugones "se mucstra en posesión de un verso refinado y exquisito que combina la perfección escultórica del gusto parnasianista con la sugerencia de visiones interiores propiciadas por cl simbolismo" (Olivio Jiménez, 332). "Holocausto", "Occánida" y "Delectación morosa" de la scric de sonetos dedicados a Tablada son bello cjemplo de estas tendencias. La excepción es "Emoción aldeana", que a manera de colofón đel libro, anticipa ese lenguaje llano de tono socarrón que caractcriza la próxima aventura poćtica de Lugones.

En 1909 publica "por venganza a la vida" el Lunario sentimental, "rcbosante de novedades y de anticipos, que no sólo se sitúa fucra de la escucla modernista sino que preludia cicrtos aspectos de la poesía vanguardista" (Phillips, 47). Al año siguiente-1910-Lugones inicia su primer intento poético de carácter nacional. Las Odas seculares "son composiciones cxtensas de molde neoclásico c intención gcórgica y nacionalista" (Olivio Jiménez, 334). La palabra vuclve a su scncillcz, acercándose más a la naturaleza y a las cosas de la vida diaria. Se trata de un lirismo más natural que se continúa en El libro fiel (1912), El libro los paisajes (1927) y Las horas doradas (1917). En estas colecciones se observa esa tendencia a la sencillez que culmina con cl Romancero (1924) y los Poemas solariegos (1927) donde el gran pocta argentino - como dice Pacheco- "no resistió la fascinación de los haikus c imitó a Tablada en las brevísimas composiciones "Los ínfimos"” (63, nota 5). Lugones cra, pues, un innovador —en los temas y en estilo-sobre todo en Los crepúsculos del jardín, que revelan ciertos temas y metáforas que constituyen una posible fuente de las audacias distintivas de Al sol y bajo la luna de Tablada; y en Lunario sentimental, donde la obsesión por la luna posiblemente sirvió de incilación al $L i$-Po de Tablada.

La traycctoria de Tablada, por su parte, parece seguir una ruta paralcla a la de Lugones. El florilegio de Tablada, siguiendo la vena baudeleriana, refleja un 
decadentismo comparable al de Las montañas de oro de Lugones. Poemas como "Misa negra", "Magna Peccatrix" tienen ese tono erótico y satánico de "La vendimia de sangre" o "Rosas del Calvario" de Lugones, aunque se trata sólo de una tendencia común en muchos poetas modernistas de fin de siglo y principios del $\mathrm{XX}-$ Reissig, Silva y Nervo, entrc otros. En México, como dice Urbina, Tablada fuc quien "introdujo entre nosotros cl nuevo estremecimiento de Baudelairc ...", siguiendo cl "alma enferma y hosca de Huysmans" (citado por M. Valdés, Obras 12). Se trata, pues, de una tendencia común de la época.

Con Al sol y bajo la luna (1918), inicia Tablada sus primeras audacias líricas que serán la base del movimiento de vanguardia en México, representado por el grupo de los "Contemporáncos"2. Es interesante que el juicio cmitido por Phillips, quien considera Los crepúsculos del jardín como un preludio de "cicros aspectos de la poesía vanguardista" (47), sea similar al de Héctor Valdés cuando apunta que Al sol y bajo la luna "marca la transición del modemismo a la poesía de vanguardia, no sólo en Tablada, sino en México" (14). Y aquí sí, la presencia de Lugones se hace patente debido posiblemente a la amistad creada a través de la participación de ambos poctas en la Revista Moderna de México; lo que llevó a Lugones a dedicarle doce sonetos de sus Crepúsculos, y a escribir el pocma preliminar del pocmario de Tablada.

Por su parte, poco despućs, Tablada introduce en la pocsía de la lengua española los haikús, o pocmas japoneses. Un día (1919) y Jarro de flores (1922) son dos volúmenes de haikú. Comparado con el resto de su producción, este nuevo estilo es significativo, por su carácter experimental, y por la influencia que cjerció en otros poctas mexicanos y latinoamcricanos, incluyendo a Lugones, que llegaron a cultivarlo. La popularidad de Tablada proviene de csta gran innovación en la poesía de nuestro continente.

Como Lugones, y posiblemente inspirado por la obsesión selénica de Lunario sentimental, Tablada dedica un libro completo al culto de la luna. $L i-P o(1920) \mathrm{es}$ una colección de "idcogramas" a la mancra de los Calligrammes (1913-1916) de Apollinaire. El libro es una alabanza a Li-Po, cl pocta chino (701-762) que, según la leyenda, se ahogó "from leaning one night too far over the edge of a boat in a drunken effort to embrace the reflection of the moon" (Giles, citado por Aldridge, 116).

\footnotetext{
${ }^{2}$ A partir de 1918, con la publicación de $A l$ sol y bajo la luna, "Tablada logra, dice Valdés, lo mejor de su poesía, y la trilogía Tablada - González Martínez- López Velarde se impone en la vanguardia poética de México. Ellos son el antecedente de los "Contemporáneos " (Obras, 17 ).
} 
El último libro de Tablada, La Feria (1928), adquicre cl matiz nacionalista cultivado por Lugones en sus Odas seculares. Es cl regreso del pocta a las raices y representa un cambio de visión poética a la manera de López Velarde, quién también le debe lo suyo a Lugones.

Tablada cs, pues, un innovador constante e incansable; y esto se explica por la concepción del arte que tenía el poeta. "Todo depende - dice Tablada- del concepto que se tenga del arte; hay quien lo cree estático y definitivo; yo lo creo en perpeluo movimiento" (citado por 0. Paz, Las perlas, 64). Tanto Tablada como Lugones perienecen a eso que Octavio Paz llama "poetas de ruptura"; cxiste en cllos una visión constante de renovación; ambos poctas han abicrto caminos antes insondables en la literatura. Federico de Onís dice de Tablada que "desde los tiempos de Gutićrrez Nájera hasta hoy, Tablada ha figurado en las avanzadas de todos los movimientos poćticos"; además, "Tablada ha persiguido abicrtamente, y con plena conciencia, una constante renovación mediante cl cultivo de todas las tendencias poćticas ... prefiriendo [como Lugones] las mås exóticas y audaces" (citado por Roggiano, "José Juan Tablada", 47); y lo mismo podríamos decir de Lugones y su impacto en la literatura de hoy.

Una vez establecida la consonancia de ambas trayectorias, convendría ahora scñalar unas cuantas semejanzas notables en tema y cstilo, y la manera en que éstos son utilizados. Lo primero que notamos al echar un vistazo a las obras de los dos poetas, es la semejanza de títulos de muchos de sus poemas - algunos idénticos. Mencionaré sólo unos cuantos. "Los fuegos artificiales" (1895) de Tablada es un poema que presenta la mctáfora audaz del pocta como un castillo de fuegos artificiales encendido que alumbra c ilumina a la humanidad. El poema se asemcja más a la metáfora que Lugones utiliza a lo largo de Las montañas de oro y específicamente "El himno a las torres" (1897), que a su "Fucgos artificiales", donde Lugones satiriza al hombre común durante una celcbración patriotera" "Romántica" (1919) de Tablada es más que una mera coincidencia de nombre con "Romántica" de Lugones, un poema dedicado "A Amado Nervo". La segunda estrofa de este pocma coincide con cl tono melancólico creado por cl contraste de luz y oscuridad de la segunda y tercera estrofas del de Tablada. El poema "Luna sentimental" de Tablada es cl que cncabeza Al sol y bajo la luna (1918); libro que además conticne un poema de Lugones a manera de prólogo dirigido al lector. Es cvidente que ambos poetas cran conscientes de que compartían cicrtas afinidades poćticas. Es como si Tablada, al utilizar abicrtamente algunos títulos de Lugones, correspondicra al argentino con un gesto de amistad.

${ }^{3}$ La interpretación que doy es similar a la de Navarro, quien ve en este poema la tendencia de Lugones a caricaturizar al hombre común. Ver pp. 135-6 de su análisis del Lunario sentimental. 
En otras ocasiones se trata tan sólo de un verso de un pocma de Tablada que repite el tílulo de un poema de Lugones. En "Magna Peccatrix" el verso 17, "La cátedra del vicjo Anakreonte" alude al pocma de Lugones "La vejez de Anacreonte"; o en el caso de "Nocturno oriental", en la estrofa 12 se lee en el verso 4 "laxo en total delcctación morosa", aludiendo a uno de los doce sonetos "Los doce gozos" que Lugones dedicara "A José Juan Tablada" en sus Crepúsculos. El soneto es "Delectación morosa".

Por su parte, Lugones corresponde al gesto del mexicano del mismo modo. En uno de sus pocmas póstumos, "Lucićrnaga" (1938), que refleja la nueva tendencia hacia la naturalcza, Lugones parece aludir al pocma "Lucićmagas" (1920) del Tablada de $L i-P o$. Vale la pena reproducirlos por su audacia expresiva.

$\begin{array}{lll}\text { La luz } & \text { de las } & \text { Luciérnagas } \\ \text { es un } & \text { blando } & \text { suspiro } \\ \text { Alternado } & \text { con pausas } & \text { de oscuridad } \\ \begin{array}{c}\text { Pensamientos } \\ \text { sombrios } \\ \text { en gotas }\end{array} & \text { que se } & \text { disueiven } \\ & \text { instantáneas } & \text { de claridad }\end{array}$

\section{LA LUCIERNAGA (Lugones)}

Chispa que en la noche

Se enciende y se apaga,

De pronto, una estrella;

De pronto, la nada.

Sombra de mi angustia,

Chispa de su gracia,

De pronto, una estrella;

De pronto, la nada ...

El uso consistente de estos modos es, en mi opinión, como un guiño del ojo que ambos se cnvian a través del texto y la poesia. Más que falta de creatividad, se trata de expresar una tendencia poćtica común, así como de estrechar los lazos de amistad que los unía. 
Sin embargo, más que esas analogías casuales, nos interesa poner en relieve la afinidad expresiva y temática cntre ambos poctas. Es en los Crepúsculos de Lugones, donde Tablada cncuentra mayor inspiración para algunos de sus pocmas de $A l$ sol y bajo la luna. El tema de la mujer a la manera lugoniana gira en torno a cstos pocmas de Tablada. La mujer de Lugones ya no es la misma de los mođernistas; es más bien, una figura escuálida, una jovencita débil rodeada de un crotismo intenso con matices decadentes. Estas muchachas son, por lo general dice Scari- "adolescentes, con formas apenas insinuadas casi todas por primera vez, dulcemente desmayadas entre la cmoción amorosa y cl temor del pecado"; y son "colegialas ojcrosas, cuyo corazón late como una paloma asustada al menor sobresalto" ("Los crepúsculos ...", 106).

En los pocmas de Tablada, además de ese crotismo intenso lugoniano, cncontramos también a esa pequeña figura femenina. En el "Nocturno oriental" de Tablada se refleja csta visión peculiar de la mujer. Pocmas como "Delcctación morosa", "Occánida", "Romántica" son algunos cjemplos. En "Cisnes negros" Lugones describe a cstas colegialas como:

\footnotetext{
Casi niñas las tres, sus brazos flojos

Con prematuro afán siegan quimeras

$Y$ asombra lo profundo de sus ojos

Y la desvastación de sus ojeras.
}

y Tablada en "En pecado morlal" describe a cstas mismas niñas precoces en su afán amoroso.

\author{
$Y$ los fervores de tu prez \\ dicen tus lánguidas caderas \\ $Y$ el surco azul de tus ojeras \\ que pintan hiedras en tu tez \\ $Y$ tus amigas de colegio \\ se turban ante el sortilegio \\ que hay en tus dedos de marfil.
}

En "Tangra" cl pocma se inicia con los siguientes versos: "¡Parces capullo y cres rosa!/ Por tu aspecto infantil." Además de los anteriores, existen otros muchos cjemplos de csta afinidad expresiva cntre Los crepúsculos de Lugones y Al sol y bajo la luna de Tablada que se podrían citar.

La afinidad temática de estos pocmas es reforzada por el uso de una de las metáforas dominantes en Los crepúsculos de Lugones. Es la metáfora del mar o 
cl océano personificada y crotizada que remplaza al Sátiro del modernismo rctórico temprano. La imagen aparece con gran intensidad en "Occánida" de Lugones (otro de los sonetos dedicados a Tablada) donde

El mar lleno de urgencias masculinas

Bramaba alrededor de tu cintura.

y en "Tangra" de Tablada, encontramos la misma imagen en la segunda estrofa.
De la intensa pasión, todo el arcano
palpita en tu misterio femenino
parvado y rosado caracol marino
donde se oye gemir un océano.

En Tablada también se refleja la actitud totalmente antimodernista de la mujer presentada cn "Emoción aldeana" de Lugones. La bella Venus, incitadora del pecado que cnloquece al pocta, es transformada, o mejor sería decir, es bajada del pedestal a la tierra, a su verdadera condición humana. "Lawn tennis" y "Mujeres que pasáis por la Quinta Avenida" de Tablada son bellos ccos del pocma que cicrra Los crepúsculos de Lugones. El segundo poema de Tablada especialmente revela csta actitud de distanciamiento hacia la mujer. El lenguaje y estilo del pocma, como ya ha scñalado Renaldi, prefigura cl futurismo vanguardista en la pocsía cspañola". En "Emoción aldeana" la imagen de la mujer es ironizada; la joven del poema cs una chica de campo "chisporroteada de pecas ..." que tiene "ojos de gata". Lugones parodia la imagen femenina de los modernistas. El lenguaje llano y áspero es utilizado para describir a esta joven en un escenario que dista mucho de ser el bello jardín paradisíaco con cl que cnvolvían los poctas modernistas a sus musas. Tablada, por el contrario, nos describe cl ambiente urbano de Nueva York, pero nos presenta a la mujer tratada con cl mismo tono irónico de Lugones, y lleno de las audacias lingüísticas y rítmicas del Lugones de Lunario sentimental. El pocma de Tablada es una visión negativa de la mujer nortcamericana frívola y carente de sensibilidad.

\footnotetext{
${ }^{4}$ Héctor Valdés, en su introducción a las Obras completas de Tablada, al comentar sobre estos poemas, sostiene que los "primeros versos de "Mujeres que pasáis ..." transforman la figura femenina creada en los años del modernismo" (15).

5 "Las palabras futurísticas no son mero tour de force ni tampoco están allí para escandalizar. La voz "fire proof", al describir a las mujeres, no sugiere frialdad ni reserva sino una resistencia ingénita que puede comunicar el aspecto de androide" (Renaldi, 255).
} 


\begin{abstract}
¿Soñais desnudas que en el baño os cae áureo Jove pluvial, ¡como a Danae? ...

$\ldots$ Mujeres "Cire proor", a la pasión inertes llenas de fortaleza, como las cajas fuertes.
\end{abstract}

De nuevo, Tablada encuentra en estas innovaciones una tendencia afín y un medio estćtico formal para expresar su nueva visión de ruptura o rechazo de la vicja retórica modernista. Vemos, cntonces, como Tablada adopta en Al sol y bajo la luna algunos de los principales clementos característicos de Los crepúsculos del jardín de Lugones: y esto se explica en función del carácter renovador y abierto de los dos poctas.

Por otra partc, Tablada también cra un gran conocedor de la litcratura francesa. En muchas ocasiones tradujo, en diversas publicaciones del país, pocmas de Baudelaire; de Proudhon; de Loüys; de Víctor Hugo, y otros. Es posible que Tablada hubicra conocido también la obra de Laforgue, tan significativa para $\mathrm{el}$ Lunario de Lugones ${ }^{6}$. Dos pocmas de El florilegio "Mascarada" y "Comedicta", publicados en 1900, parecen indicar que tablada tenía conocimiento de Les complaintes de Laforgue, donde la figura típica de Picrrot ocupa un lugar relevante. Este personaje, venido de la "Commedia dell'arte" italiana, cobró importancia en cl siglo XVIII en Francia con la pintura de Watteau (1684-1721), y gozó de gran popularidad hacia fines del XIX?. Los pocmas de Tablada recrean también este personaje que, comocn Laforgue, manifiesta cierta actitud irónica de farsa, aunque suavizada con matices sentimentales. Además del tono, la semejanza en la métrica y la rima de uno de los pocmas de Laforgue ("Locutions des Pierrots") con los poemas de Tablada, nos lleva a pensar que el mexicano adoptó no sólo cl tema, sino también la forma del pocma de Laforgue ${ }^{8}$.

\footnotetext{
${ }^{6}$ Allen W. Phillips en 1958 publicó un estudio sobre las influencias del francés Laforgue en el Lunario sentimental de Lugones. Su estudio, debo mencionar, me ha sido de gran utilidad para este trabajo.

${ }^{7}$ Para un resumen de la trayectoria de este personaje, ver la nota 5 del estudio de Robert M. Scari titulado "Algunos procedimientos técnicos y temáticos del Lunario sentimental de Lcopoldo Lugones” en CIIA 263-264 (1972).

${ }^{8}$ Carlos Martínez Rivas ofrece una excelente perpectiva de la trayectoria artística de Wattcau y de su influcncia en los poctas franceses del XIX. Comentando sobre el poema de Darío "Mañana", dedicado a Watteau, aclara que no es Verlaine, sino Baudelaire "quien fletó su barco con destino a esa isla. (Véase el poema 'Un voyage a Cythere', en Les fleurs du mal, inspirado en cl cuadro de Watteau del Musco de Louvre, El embarco para Citeres)" (445).
} 

Ah? tout le long du coeur
Un vieil ennui m'efflure ...
$C^{\prime}$ est avis qu'il est l'heure
De renaître moqueur.

En "Comedieta" Tablada traduce a la redondilla española la métrica francesa utilizada por Laforgue.

\author{
En un parque de Watteau \\ que llena de rosas junio \\ y que un claro plenilunio \\ con su luz opalizó.
}

Sin duda Tablada conoció a Wattcau y su obra pictórica; lo demucstran varios poemas de El florilegio, y espccialmentc el "Soncto a Wattcau" (1889). El pocma cs una réplica a un pocma de Baudclaire, "Un voyage a Cythére", escrito en honor al pintor del siglo XVIII, quien dedicó algunos de sus lienzos más famosos a la figura del Picrot.

Siendo México una "pequeña Francia" a finales de siglo, es probable que cuando Tablada conoció la obra de Laforgue, sc interesara también por el personajc de la "Commedia dell'arte" italiana, siguicndo una nueva pauta en la pocsía mexicana. Lo mismo podemos decir de Lugones, cuyo Lunario sentimental presenta más de una coincidencia con Laforguc; y esto ya ha sido bien estudiado por Allen W. Phillips'. Sin cmbargo, es posible que los pocmas tempranos de Tablada (1900) hayan sido la mecha que prendió fucgo al Lunario de Lugones. La afirmación no carece de fundamento. Los pocmas de Lugones dedicados a la figura de Pierrot perienecen al Lunario sentimental publicado en 1909, y cuando muy temprano podrían ser fechados en 1904, fecha de publicación del "Himno a la luna" ". Además, existen en los pocmas de Lugones varios elementos que indican que éste conocía los pocmas de Tablada. En "A las máscaras" de Lugones, hay más que una coincidencia de título con "Mascarada" de Tablada. Ambos poemas coinciden en contenido y forma.

\section{MASCARADA \\ El corsé de terciopelo \\ y la máscara de raso}

\section{A LAS MASCARAS}

II

Mimos de terciopelo

Burlas del antifaz

\footnotetext{
9 Ver la nota 6 de este ensayo.

${ }^{10}$ La fecha de publicación que da Obligado al "Himno a la luna" es 1904 . Ver la nota al pie de la página 205 de las Obras poéticas completas de Lugones.
} 
resbalaron hasta el suelo desprendidos de su lazo.
Labios de caramelo

Medianamente audaz.

El pocma de Tablada tiene versos de ocho sílabas, el de Lugones siete. Los dos pocmas son una variación de la redondilla con rima $a b a b$, y $\mathrm{cn}$ ambos casos cl primer verso rima con el tercero en "elo-clo". Lo mismo sucede con "Odeleta a Colombina" de Lugones, y "Comedieta" de Tablada. En este caso, ambos poctas siguen la forma tradicional de la redondilla, o sea, con rima $a b b a$.

Estimo que las evidencias dadas sugieren y refuerzan nuestro argumento que csbozamos al principio de este ensayo. La amistad entre Tablada y Lugones no se limitó sólo a dedicar pocmas. Su visión poćtica y su concepción del arte (cn perpclua renovación) condujo a ambos poctas por derrotcros similares; y una forma de reconocer esta afinidad es a través del concepto de "pocsía abierta", si se me permitc utilizar cl término; y con csto enticndo algo similar al concepto de "novela abicrta" que se inicia con Galdós y cobra vitalidad entre los escritores latinoamericanos del llamado "boom".

El critcrio utilizado en el estudio de estas fuentes literarias coincide con el de Amado Alonso, quien sostiene que

las fuentes literarias deben ser referidas al acto de creación como incitaciones o motivos de reacción. El poeta no repite; replica [y en este sentido he ulilizado el término]. Y es claro que sólo captaremos todo el sentido de la réplica si nos es conocida la incitación (302).

En este sentido, los poemas de Tablada le sirvieron a Lugones, posiblemente, como "incitación" para expresar (rcplicar) su obsesión por la luna en Lunario sentimental. Scría válido decir, cntonces, que ambos poctas intercambian "incitaciones".

En función de este intercambio también se podría conjeturar que cl libro de $\mathrm{Li}$ Po, con cl cual Tablada se hace eco de csa obsesión sclénica, sca una réplica al (y no del) Lunario de Lugones.

El Lunario sentimental conticne dos composiciones en las cuales el protagonista se suicida o piensa en cllo - según Navarro- "porque no pucde integrar la realidad de la vida con la ilusión" (229)". En "El pescador de sirenas", una narración burlona de la tragedia de un pobre infeliz que, empeñado en pescar los reflejos de las nubes que proyectaban imágenes de "bellas sirenas", se arrojó al agua y se ahogó a pesar de que sabía que sólo cran reflcjos y no realidad.

\footnotetext{
"Navarro sugiere que estas narraciones podrían haber sido un preludio del trágico final de Lugones. "Nosotros creemos, ... que la frustración intelectual y espiritual que sufrió el pocta al no poder integrar la realidad con la irrealidad quizá haya contribuido en algo a la causa o causas inmediatas de su suicido" (152).
} 
Esto nos recucrda la leyenda en torno al pocta chino Li-Po, que murió ahogado cn un lago tratando de alcanzar la luna reflejada en las aguas. "Su vida — dice Valdés-, un tanto licenciosa, lo inmortalizó como el "bohemio" del siglo VIII, amante del vino y las mujeres" (21). Es posible que Tablada, quien siempre admiró las culturas orientales, haya encontrado en estas narraciones y en Lunario, cl incentivo y fórmula de cxpresión de una obsesión compartida con Lugones y Laforguc.

Debido a las limitaciones de este cnsayo, se nos escapa incluir muchas otras afinidades comunes, especialmente en cuanto a técnicas de cstilo y audacias líricas se reficre. Mencionaré sólo algunas. El uso de vocablos extranjeros con fines de rima cs un recurso común en ambos poctas; lambićn cl uso especial de argucias gráficas como en el verso "un sapo ... sOnOro" de $L i-P o$, con lo que Tablada transmite "así una impresión de vértigo maléfico" (Mitre, 676); por su parte, Lugones, en "Los fuegos artificiales" se burla de la muchedumbre, de los "rOstrOs đe las mujeres" atónitas ante una celcbración.

Crecmos demostrar con las páginas precedentes, que la trayectoria poćtica de Lugones y Tablada refleja una afinidad poética basada en una actitud de constante innovación y apertura hacia todas las corrientes litcrarias. Las semejanzas temáticas y estilísticas, además de los casos específicos de influencia dirceta, muestran claramente el reconocimicnto mutuo de esta actitud ante el arte y la pocsia. 
